\title{
Increased Misuse of Alcohol and Drugs among Unemployed during COVID-19 Pandemic
}

\author{
Richard E. Hunter ${ }^{1}$, Richard A. Nida ${ }^{2}$ \\ ${ }^{1}$ Communication Department, Maryville University, St. Louis, Missouri, USA \\ ${ }^{2}$ Public Relations, Authentic Strategic Partners, Chapel Hill, North Carolina, USA \\ Email: rich@authenticstrategicpartners.com,rick@authenticstrategicpartners.com
}

How to cite this paper: Hunter, R. E., \& Nida, R. A. (2021). Increased Misuse of Alcohol and Drugs among Unemployed during COVID-19 Pandemic. Open Journal of Business and Management, 9, 1480-1491. https://doi.org/10.4236/ojbm.2021.93079

Received: April 13, 2021

Accepted: May 28, 2021

Published: May 31, 2021

Copyright (c) 2021 by author(s) and Scientific Research Publishing Inc. This work is licensed under the Creative Commons Attribution International License (CC BY 4.0).

http://creativecommons.org/licenses/by/4.0/

\begin{abstract}
Rampant unemployment in the United States brought on by the COVID-19 pandemic has had an enormous detrimental effect on the financial well-being of millions of Americans and their families. Personal concerns about these financial disruptions and social isolation as a precaution against the pandemic have heighted stress particularly among vulnerable groups like the unemployed. High stress situations are known triggers for maladaptive coping behaviors like use/overuse of alcohol, prescription medications, and street drugs. This study of 600 unemployed individuals found substantial increases in all three categories of mood-altering substances. Using adapted addiction symptom measurement items from the most recent Diagnostic and Statistical Manual (DSM-5), the researchers established comparative addiction risk profiles for each substance category. Further, the results of the study offer preliminary insights into substance abuse patterns across two and even all three of the substance categories.
\end{abstract}

\section{Keywords}

Unemployment, COVID-19, Addiction, Alcohol, Drugs

\section{Introduction}

While to-date the COVID-19 pandemic crisis cannot be considered over, as vaccination rates rise, pandemic metrics for the U.S decrease, and the economy continues to recover, a space emerges that allows reflection on the myriad of COVID-19 impacts on the U.S. populace beyond that of virus infection, suffering, and death. One of the most notable non-medical consequences of the pandemic has been the staggering loss of employment by millions of U.S. workers. This once-in-a-century COVID-19 pandemic catapulted U.S. unemployment 
within two short months from a February 2020 low of 3.5 percent to a stratospheric level of more than 14 percent by April 2020 (Congressional Research Service, 2021). In its wake, millions of newly-unemployed U.S. residents became financially concerned about future prospects. From there, over a period of a year unemployment eventually subsided to a March 2021 level of 6 percent (Bureau of Labor Statistics, 2021). The personal devastation has been immense and has taken many forms.

Unemployment has long been recognized as a catalyst for a host of individual and family social ills that influence community and the larger society. The impacts of unemployment on families include a wide range of negative pressures including financial hardship, strained relationships, poorer health, housing stress, and children's stunted development (McClelland, 2000). Prolonged unemployment tends to spawn ill-adaptive coping behaviors that can ultimately prove nearly as destructive as the COVID-19 virus itself. A combination of prolonged social isolation caused by the pandemic and financial insecurity caused by unemployment may have led to a perfect storm and increased the desire to temporarily escape reality. This reality escape may have been manifested through the overuse (or abuse) of alcohol, prescription medications, or street drugs, such as marijuana.

National news reports of increased alcohol use during the COVID-9 time-period were numerous. A study by RTI International found that during the period of the highest unemployment referenced above, survey participants reported a 29 percent increase in terms of their average number of drinks per day, and they also significantly increased their rates of excessive drinking and binge drinking (Barbosa, Cowell, \& Dowd, 2020). Prescription drug usage for habit-forming stress-related drugs to treat anxiety also increased dramatically (34 percent) for roughly the same time period as reported by Newsweek (2020). While increased street drug usage is much harder to assess, a reasonable proxy measure may be the sheer number and breadth of its reporting with the American Medical Association summarizing it this way in a 40 -state summary brief: "The media reports below cite data from multiple and varied sources, including national, state and local public health agencies, law enforcement, emergency medical services, hospitals, treatment centers, research journals and others" (American Medical Association, 2021). These reports indicate that for some who have been socially isolated for extended time periods, they were consuming alcohol/drugs more frequently and in greater volume than before the pandemic. If a person also was unemployed, that assumption could be even more compelling.

\section{Research Objectives}

The researchers sought to explore substance usage (abuse) during the COVID-19 pandemic among a group most intensely affected by its financial and social isolation consequences, the unemployed. The study was designed with the follow- 
ing objectives: to identify the prevalence of self-reported alcohol usage, prescription medication misuse, and street drug usage during the pandemic; to determine if usage of one or more of the substances had significantly increased during the time period; to examine addiction risks for this group of unemployed people; and to introduce the prospect that those who were unemployed and most vulnerable might be engaged in multiple substance dependencies.

\subsection{The Poll}

The poll consisted of eleven unemployment-related and substance usage-related questions, and a bundled series of demographic questions provided by the Pollfish sampling company. The poll sought to identify respondents' length of unemployment, their use of the three categories of substances under study, and to elicit responses that would indicate the presence of addiction symptoms.

A national poll of 600 unemployed individuals was commissioned through the Pollfish polling service, administered through a myriad of mobile apps among cell phone users, and stratified to assure national geographic representation. The poll was deployed and completed on March 17, 2021. There was a sample error variance of $\pm 4 \%$.

More than a third (38\%) of the Pollfish sample of 600 unemployed respondents had been unemployed for 180-days or longer (See Figure 1). Three-fourths (75\%) of the respondents reported that their unemployment was caused by the COVID-19 pandemic, either because their employer closed the business or issued layoffs (37\%); they contracted COVID-19 (25.3\%); or they were forced to close their own business (12.8\%) (See Figure 2). Half of the sample respondents

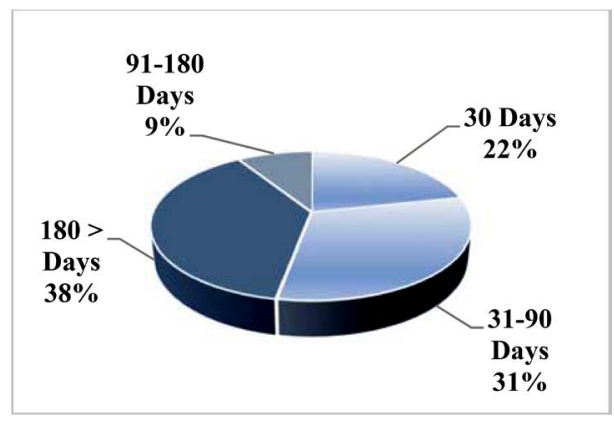

Figure 1. Length of COVID-19 Unemployment.

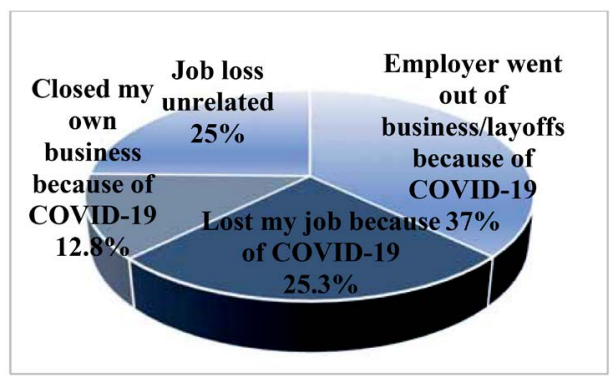

Figure 2. Cause of COVID-19 Unemployment. 
reported (52\%) either had no health care insurance beforehand (12\%) or lost their health care coverage (40\%) due to COVID-19.

The largest unemployed group $(\mathrm{N}=99)$, was unable to be classified within an established career category but were presumed to represent former employees of the "Gig economy." Demographically, they were younger, single, and more than half had been unemployed for the longest time-period, 180-days or longer. To a lesser extent, Health Care and Public Support $(\mathrm{N}=64)$, Public Education $(\mathrm{N}=$ 47), Finance and Insurance $(N=36)$, Information Services $(N=29)$, Retail $(N=$ 27), Arts, Entertainment \& Recreation $(\mathrm{N}=25)$, and Software $(\mathrm{N}=23)$ were the most frequently reported former careers of the sample respondents. A large Miscellaneous category $(\mathrm{N}=250)$ was created in order to collapse a sizable number of classified career categories with a minimal number of respondents into one, given that each individual classification category would have been too small to warrant display (See Figure 3).

\subsection{Self-Report Instrument}

The researchers adopted well-known addiction symptom measurement items used by the most recent version of the Diagnostic and Statistical Manual (DSM-5) (American Psychiatric Association, 2013), the industry standard for diagnosing mental health and addiction-related disorders. After selecting those items that tended to have universal appeal across most, if not all, existing addiction categories (e.g., alcohol, drug, gambling, etc.) and revising them to fit each substance usage behavior, the researchers settled on a total of nine measurement items that met the face validity requirement. As an example, the alcohol-related symptoms are listed below.

Selected DSM-5 Measurement Items:

- Drank more frequently from than intended.

- Spent a lot of time drinking.

- Drank more to get the same effect.

- Wanted to drink so badly, couldn't think of anything else.

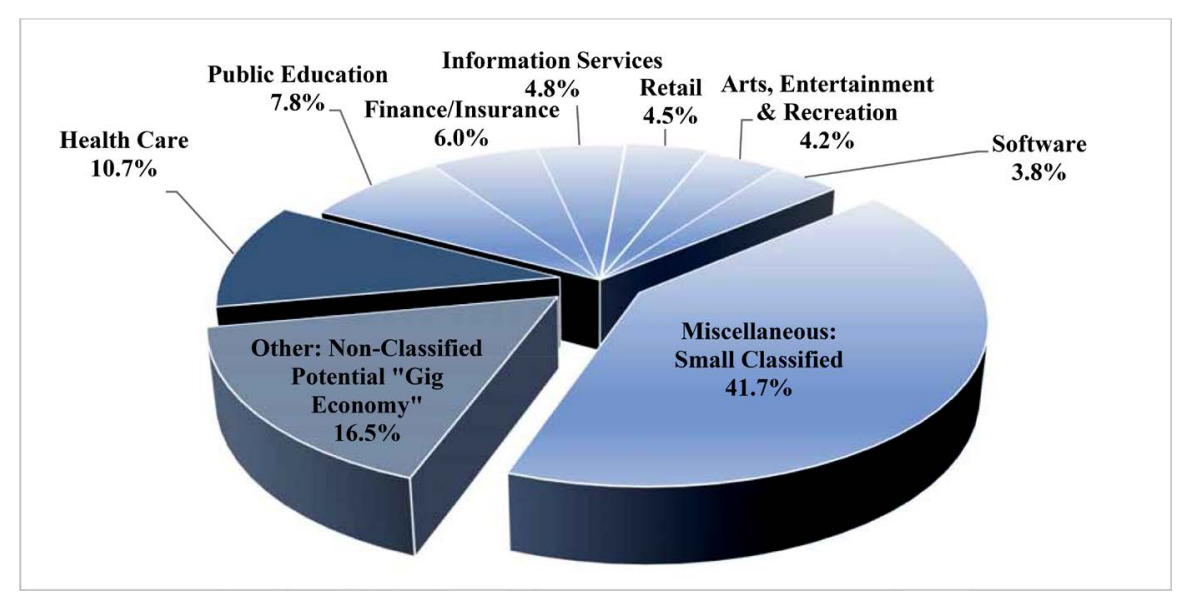

Figure 3. Unemployed study sample by career classification. 
- Gave up other activities to drink.

- Tried to quit or cut down (but couldn't).

- Continued to drink despite problems caused by drinking.

- Continued drinking caused family, job or legal problems.

- Drank the next morning to ease withdrawal symptoms.

The remaining question requested an estimate of an increase in substance usage, if any, during the COVID-19 pandemic.

The study adopted the DSM- 5 scoring process for identifying addiction behavior from the completed poll data. The scoring used a simple symptom counting process, the more symptoms selected, the greater likelihood that an unemployed respondent exhibited addiction behaviors. While the DSM-5 symptom categories (e.g., Mild, Moderate and Severe) were intended for establishing an actual diagnosis, the researchers opted, in the absence of a clinical face-to-face interview and additional related clinical information, to categorize: Mild, Moderate, and High as addiction "Risk-Groups," utilizing the same symptom count criteria.

\section{Results}

The following items summarize the major findings from this study:

1) One of the primary research objectives of this study was to determine whether substance usage had increased during the COVID-19 time-period, and if so by how much. This research validates that widespread public notion (See Figure 4). The reported increase in substance usage during the COVID-19 pandemic ranged from $30 \%$ to nearly $40 \%$ depending on the substance. Alcohol usage recorded the lowest increase at $30 \%$, while prescription medication misusage rose to an estimated $35 \%$, and street drug usage increased by a reported $39 \%$.

2) The consumption of alcohol within the U.S. culture is nearly ubiquitous. More than 7 in 10 of the unemployed sample respondents (72\%) indicated that they had consumed alcohol during the COVID-19 time-period (See Figure 5). The study respondents said that beer was the preferred choice (38\%), followed by hard liquor $(33 \%)$ and wine (29\%).

3) One in $5(21 \%, N=126)$ of the unemployed sample revealed mild, moderate

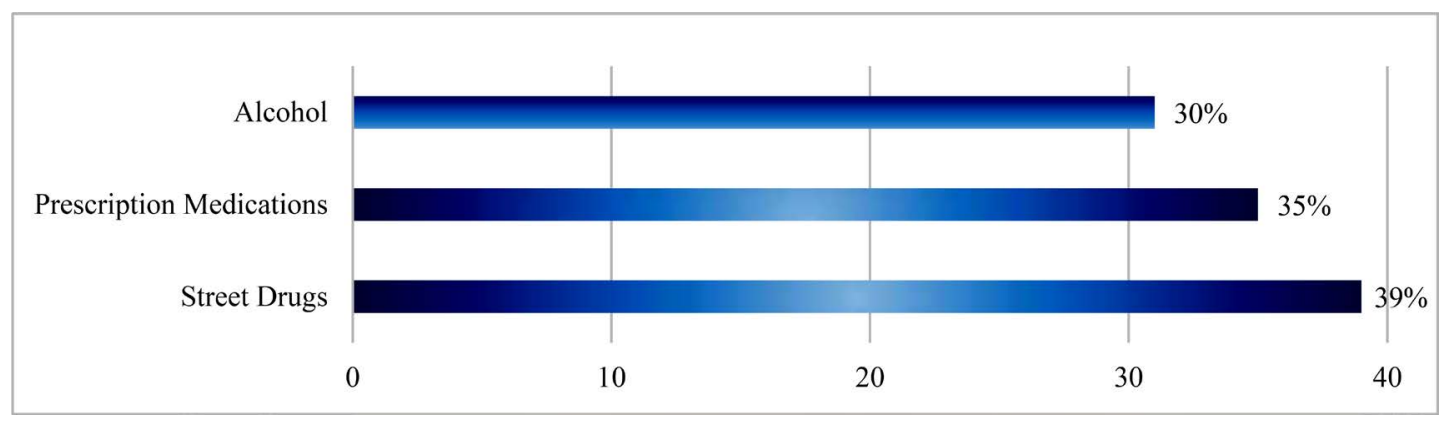

Figure 4. Estimated Increase in substance consumption among the COVID-19 unemployed. 


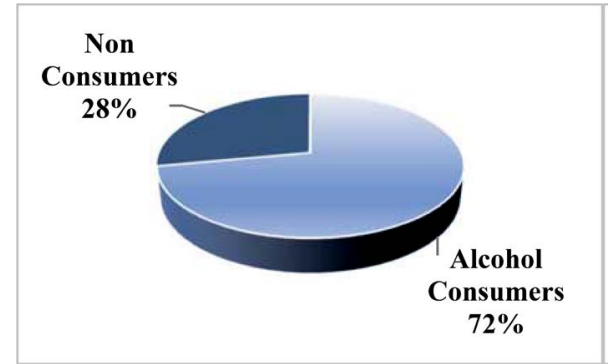

Figure 5. Prevalence of Alcohol Use among Unemployed during COVID-19.

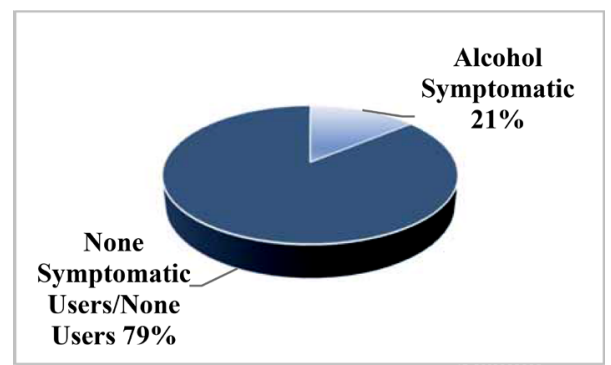

Figure 6. Prevalence of Alcohol Addiction Symptoms during COVID-19.

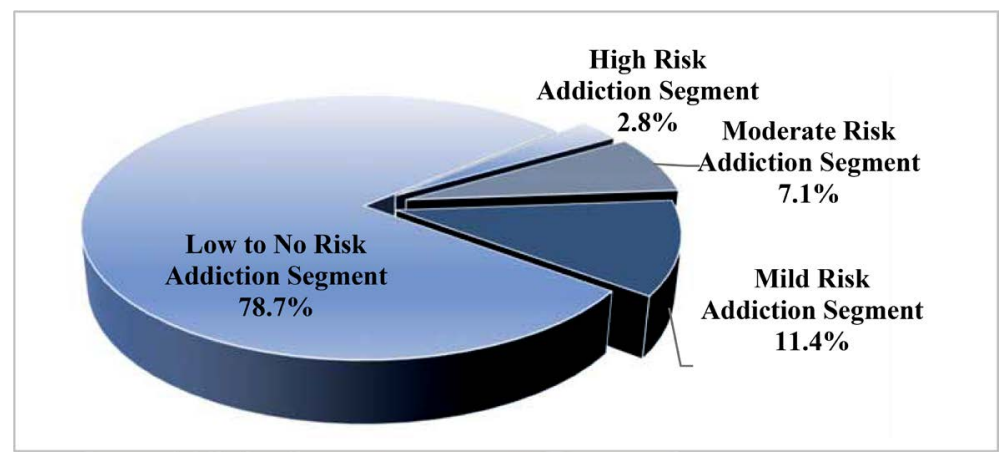

Figure 7. Alcohol addiction at-risk segments among unemployed during the COVID-19 Pandemic.

to high risk to the addiction to alcohol, based on their symptomatic profiles (See Figure 6).

4) When the DSM-5 scoring procedure was applied to diagnostically qualifyingsymptomatic alcohol users (e.g., reporting two or more symptoms) in this sample, the following was reflected: 
found that more than 30 percent of the unemployed sample (31.5\%) admitted to doing so (See Figure 8). A majority of these respondents (57\%) also proved symptomatic. The consumption of pain killers topped the list of prescription medications that were abused (57\%), following by a triad of psychotropic and sleep medications (Antidepressants, 47\%, Sleeping pills, 46\% and Sedatives, $43 \%)$. Xanax, a sedative, was the most frequently mentioned brand name prescription medication.

6) When the DSM-5 scoring procedure was applied to diagnostically qualifying symptomatic prescription medication users (e.g., reporting 2 or more symptoms) in this sample, the following was reflected:

$\begin{array}{llll}\text { Eligible } & \begin{array}{l}\text { Diagnostic } \\ \text { Abusers }\end{array} & \begin{array}{l}\text { Meds } \\ \text { Sample }\end{array} & \text { Total } \\ \text { Mild Risk (2 - 3 Symptoms) } & \mathrm{N}=64 & 36.5 \% & 10.9 \% \\ \text { Moderate Risk (4 - 5 Symptoms) } & \mathrm{N}=31 & 17.7 \% & 5.2 \% \\ \text { High Risk (6 > Symptoms) } & \mathrm{N}=11 & 6.2 \% & 1.8 \%\end{array}$

(See Figure 9 and Figure 10)

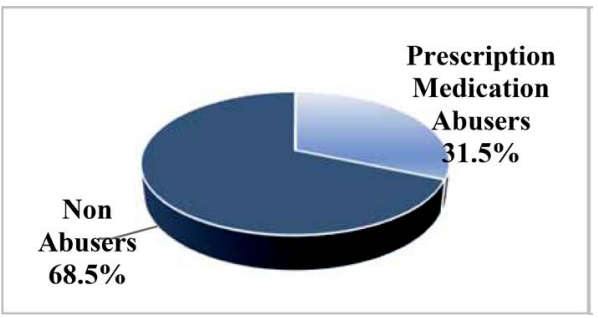

Figure 8. Prevalence of prescription medication abuse during COVID-19.

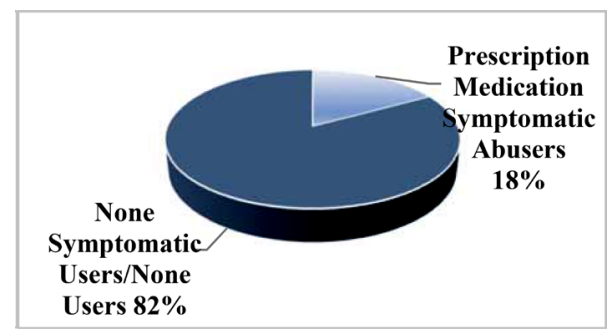

Figure 9. Prevalence of prescription medication addiction symptoms during COVID-19.

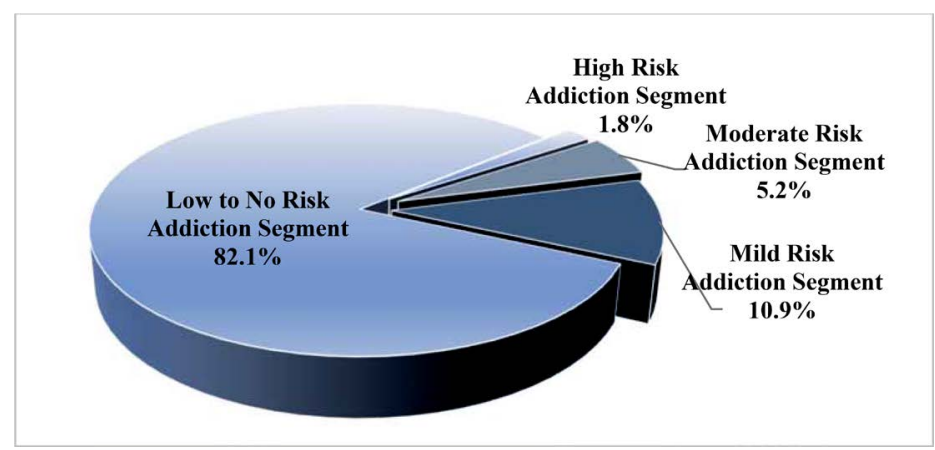

Figure 10. Prescription medication addiction at-risk segments among unemployed during the COVID-19 pandemic. 
7) The prevalence of prescription medication abusers $(18 \%, \mathrm{~N}=106)$ is similar to the number of symptomatic alcohol abusers $(21 \%, \mathrm{~N}=126)$, yet these respondents reflect a somewhat lower proportion of Moderate Risk and High-Risk profiles (e.g., 47\% Alcohol/40\% Prescription Medication).

8) "Street drugs" encompasses many of the prescription medications, outlined in prescription medication abuse section, plus street drugs currently illegal in most states, most notably marijuana - the most frequently used substance in this category. By a nearly identical prevalence percentage to prescription medication abuse, $32.5 \%$ of the unemployed sample reported that they had used street drugs during the COVID-19 pandemic (See Figure 11). An approaching majority of these respondents (46\%) also proved symptomatic, overwhelmingly using marijuana (79\%), followed by pain killers (39\%), and then sedatives (36\%), and hallucinogens (34\%).

9) When the DSM-5 scoring procedure was applied to diagnostically qualifying symptomatic street drug users (e.g., reporting 2 or more symptoms) in this sample, the following was reflected:

$\begin{array}{llll} & \begin{array}{l}\text { Diagnostic } \\ \text { Eligible }\end{array} & \begin{array}{l}\text { Street Drug } \\ \text { User }\end{array} & \begin{array}{l}\text { Total } \\ \text { Sample }\end{array} \\ \text { Mild Risk (2 - 3 Symptoms) } & \mathrm{N}=56 & 16.9 \% & 9.5 \% \\ \text { Moderate Risk (4 - 5 Symptoms) } & \mathrm{N}=19 & 10.0 \% & 3.2 \% \\ \text { High Risk (6 > Symptoms) } & \mathrm{N}=11 & 4.0 \% & 1.8 \%\end{array}$

(See Figure 11 and Figure 12)

The prevalence of street drug abusers $(14.6 \%, \mathrm{~N}=86)$ was somewhat less than the number of symptomatic alcohol abusers $(21 \%, \mathrm{~N}=126)$ and slightly less than prescription medication abusers $(18 \%, \mathrm{~N}=106)$. These respondents

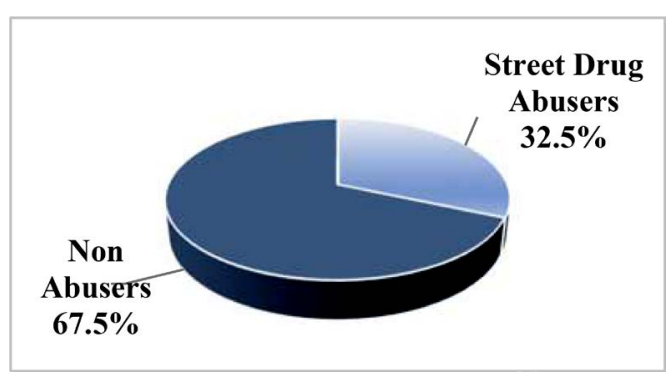

Figure 11. Prevalence of street drug abuse during COVID-19.

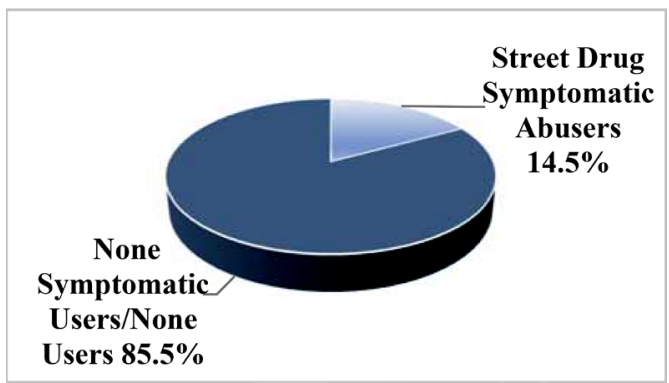

Figure 12. Prevalence of street drug addiction symptoms during COVID-19. 
reflected a similar proportion of Moderate-Risk and High-Risk profiles (e.g., 47\% Alcohol/40\% Prescription Medication/35\% Street Drugs) (See Figure 13).

10) The degree of cross-platform substance usage by long term COVID-19 respondents was compelling. A majority of the symptomatic unemployed sample, (55\%) can be described as a single substance abuse consumer (e.g., Alcohol $(\mathrm{N}=217)$, Prescription Medication $(\mathrm{N}=23)$, and Street Drug usage $(\mathrm{N}=17)$, for a total of 257 respondents. However, the prevalence of multi-substance abuse consumers included the following:

Alcohol Prescription Medication combination

$$
\begin{array}{ll}
\mathrm{N}=52 & 11.0 \% \\
\mathrm{~N}=60 & 13 \% \\
\mathrm{~N}=10 & 2 \%
\end{array}
$$$$
\text { Alcohol Street drugs combination }
$$

Prescription Medication Street Drugs combination

Alcohol Prescription Medication Street Drugs combination N $=91 \quad 19 \%$

11) A significant number of the symptomatic substance users (45\%) within this unemployed sample revealed a dual (or triple) substance usage pattern typified by two or more symptoms in at least one of the three substance categories. While there may be some conceptual overlap between the prescription medication responses and those responses to street drugs, the broad swath of symptoms across substance measurement categories suggests serious health-related, psychological

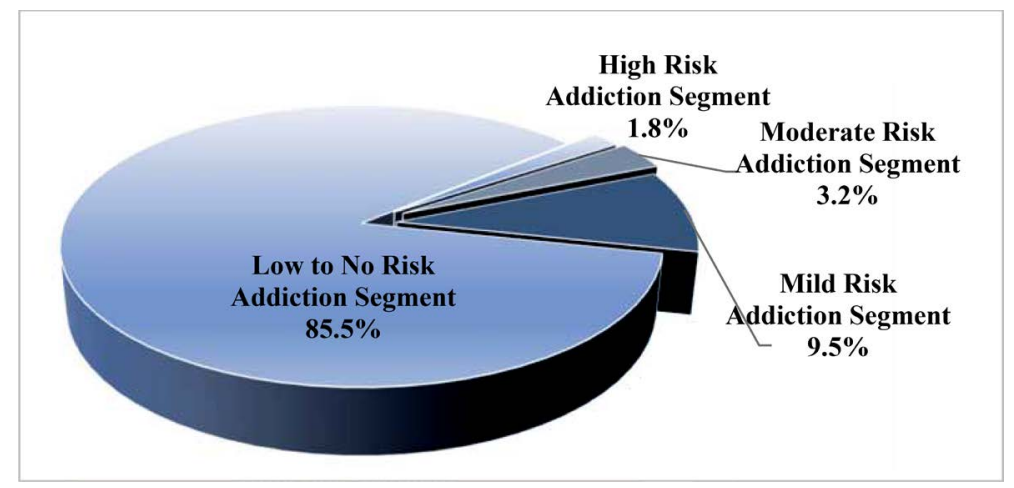

Figure 13. Street drug addiction at-risk segments among unemployed during the COVID-19 Pandemic.

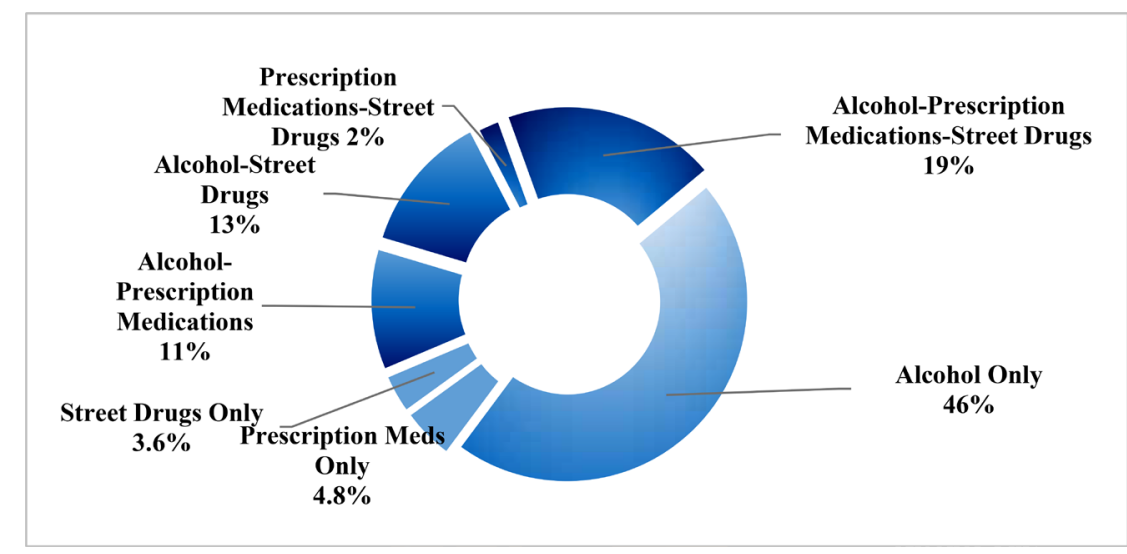

Figure 14. Single and multi-substance at-risk addiction groups among COVID-19 unemployed. 
well-being, and social ills associated with individual depleted functioning and the potential for criminality needed to support this breadth of addiction (See Figure 14).

12) In all, 470 unemployed respondents of the 600 polled (78\%) revealed one or more addiction related symptoms when assessing their alcohol, prescription medication, and street drug usage habits during the COVID-19 pandemic. An unduplicated count of symptomatic substance users, again defined as reporting two symptoms or more for a given substance (e.g., alcohol, prescription medications, or street drugs) revealed that a third of the sample (34\%) can be found in the Mild (22.6\%), Moderate (8.3\% or High-Risk (3.2\%) Groups for substance addiction (See Figure 15).

13) While many of these respondents, even those with symptoms across more than one substance category, rest within the Mild-Risk level, a sizable number represent consumption patterns that place them at higher risk for ongoing addiction, notably the combined Moderate-High-Risk groups at 11.5\% (See Figure $15)$.

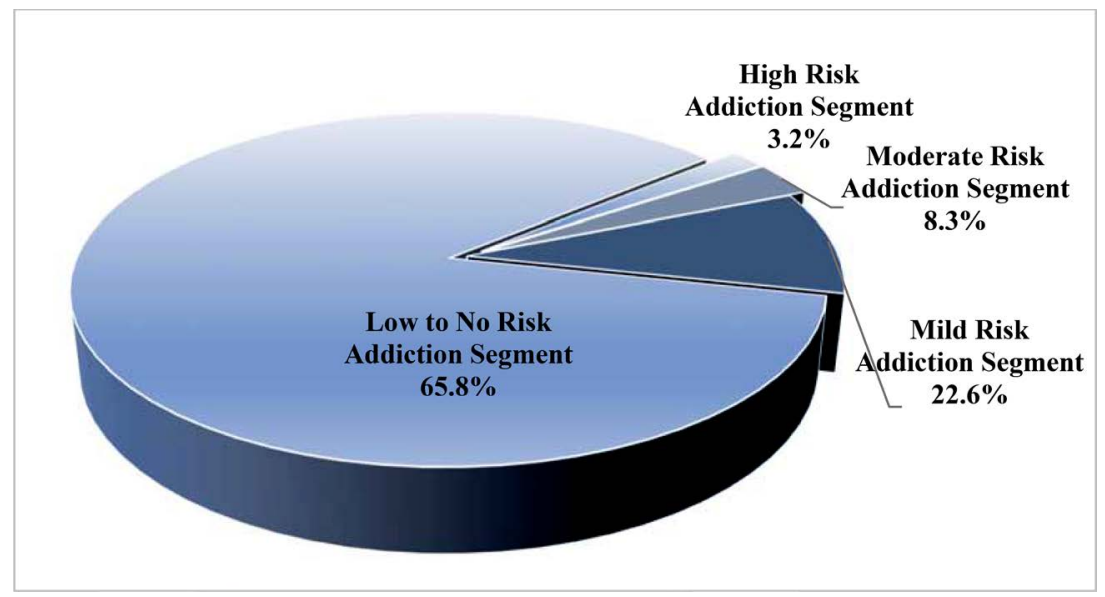

Figure 15. Symptomatic substance abuse among unemployed during the COVID-19 pandemic.

\section{Conclusion}

The emergence of the COVID-19 pandemic in early 2020, with its daily tally of massive infection, suffering, and death spawned a financial collapse of the U.S. economy with massive ensuing unemployment. With unemployment came personal financial hardship and excessive stress exacerbated further by public health admonitions and governmental restrictions to socially isolate in order to help control the pandemic. The researchers sought to explore substance usage (abuse) during the COVID-19 pandemic among the unemployed who may have employed substance use as coping mechanisms during the crisis.

The study that polled 600 unemployed individuals had four objectives:

1) To identify the prevalence of self-reported alcohol usage, prescription medication misuse, and street drug usage. The study established baseline usage 
percentages for the target group across the three substance categories suitable for comparison in future studies.

2) To determine if usage of one or more of the substances had significantly increased during the time period. As expected, usage of all three substance categories was elevated. Perhaps unexpectedly, prescription drug misuse appeared particularly alarming, with the brand name Xanax, a sedative, mentioned as abused most frequently.

3) To examine addiction risks for this group of unemployed people. Mild, moderate, and high-risk groups were enumerated for each category of substance use/abuse. Applying the established percentages of each risk group from the sample to the entire unemployed population in the U.S. may help define the parameters of the extant problem.

4) To introduce the prospect that those who were unemployed and most vulnerable might be engaged in multiple substance dependencies. Startlingly, those with multi-substance symptoms approached nearly half $(45 \%)$ of the total symptomatic substance abuse sample.

Many of the individuals in the Moderate and High-Risk groups for each of the three symptomatic substance categories would likely benefit from mental health or substance abuse services of some sort. The nature of the necessary services and the length of service time were not pursued in this study. However, the fact that 12 percent of the sample reported having no medical insurance before the pandemic and 40 percent reported losing health insurance during the pandemic appears problematic for receiving any services whatsoever. Even those with some health insurance may have insufficient mental health or substance abuse treatment provisions.

\section{Limitations of Research}

The current self-report study used 600 respondents. A larger follow-up group study needs to be conducted to validate these findings. More research into these issues obviously needs to be conducted in order to assist policy makers as they work to address the issues associated with COVID-19 induced unemployment and their resultant consequences.

\section{Conflicts of Interest}

The authors declare no conflicts of interest regarding the publication of this paper.

\section{References}

American Medical Association (2021). Reports of Increases in Opioid- and Other Drug-Related Overdose and Other Concerns during COVID Pandemic. AMA, Advocacy Resource Center.

https://www.ama-assn.org/system/files/2020-12/issue-brief-increases-in-opioid-related -overdose 
American Psychiatric Association (2013). Diagnostic and Statistical Manual of Mental Disorders, Fifth Edition: DSM-5. Arlington, VA: American Psychiatric Publishing. https://doi.org/10.1176/appi.books.9780890425596

Barbosa, C., Cowell, A. J., \& Dowd, W. N. (2020). Alcohol Consumption in Response to the COVID-19 Pandemic in the United States. Journal of Addiction Medicine. https://doi.org/10.1097/ADM.0000000000000767

Bureau of Labor Statistics, Department of Labor (2021). The Employment Situation-March 2021. https://www.bls.gov/news.release

McClelland, A. (2000). Effects of Unemployment on the Family. The Economic and Labour Relations Review, 11, 198-212. https://doi.org/10.1177/103530460001100204

Slisco, A. (2020). Americans Are Taking 34 Percent More Anxiety Meds Since Coronavirus Pandemic Started, Study Says. Newsweek.

https://www.newsweek.com/americans-are-taking-34-percent-more-anxiety-meds-sinc e-coronavirus-pandemic-started-study-says-1498189

Unemployment Rates during the COVID-19 (2021). Congressional Research Service R46554 Updated March 12, 1. https://crsreports.congress.gov 